\title{
Editorial
}

\section{The rise and fall of the atypical antipsychotics}

\author{
Tim Kendall
}

\begin{abstract}
Summary
The antipsychotics brought hope and optimism to people with schizophrenia and to those who care for them. There have been successive classes of antipsychotics used by the pharmaceutical industry to persuade doctors and patients that 'new' is better. Evidence is growing that the primary purpose of these fabricated classes is for marketing. It is time we stopped using these expensive labels - they are all just antipsychotics.
\end{abstract}

\section{Declaration of interests}

T.K. receives about $£ 1.4$ million per year from the National
Institute for Health and Clinical Excellence (NICE) to develop clinical practice guidelines for the National Health Service in England and Wales. He also receives funding/grants from other bodies including the Academy of Medical Royal Colleges, the Department of Health and NICE International to undertake systematic reviews or guideline development. T.K. is a co-opted member of the Council of the Royal College of Psychiatrists and contributed to the development of the College Report CR148 on psychiatrists' relationship with the pharmaceutical industry.
Professor Tim Kendall is the director of the National Collaborating Centre for Mental Health, Royal College of Psychiatrists; medical director and consultant psychiatrist, Sheffield Health and Social Care NHS Foundation Trust; and visiting professor, University College London. Tim chaired the first NICE guideline on schizophrenia and facilitated the recent update of the schizophrenia guideline as well as many others. He chaired the first national quality standard on dementia and facilitated the first NICE guideline produced outside the UK. He also works with the homeless team in Sheffield.

In this Journal, Girgis et al ${ }^{1}$ report the results of a 9-year follow-up of a randomised controlled trial of the first 'typical' antipsychotic, chlorpromazine, compared with the first prototypical 'atypical', clozapine, in 160 people with treatment-naive, first-episode schizophrenia in China. Believing that the atypicals were more efficacious, had fewer side-effects and may even be 'neuroprotective', decreasing the long-term deterioration and negative symptoms often associated with schizophrenia, the authors hypothesised 10 years ago that patients randomised to clozapine would have better long-term outcomes than those randomised to chlorpromazine. The short answer is that there is not much of a difference.

Although clozapine may be better tolerated, there were no differences on primary outcome measures, including time to remission, time spent in remission and symptom severity, by 12 months and at 9 years' follow-up. ${ }^{1}$ Girgis et al clear a little of the fog generated by the mass of cleverly constructed trials and selectively published ${ }^{2}$ data supporting a marketing strategy of 'smoke and mirrors' ${ }^{3}$ that has underpinned our collective misunderstanding about the so-called atypical antipsychotics.

With the exception of clozapine for treatment-resistant schizophrenia, ${ }^{4}$ the atypicals, as a group of antipsychotics, are no more efficacious for schizophrenia than the typicals, whether it is chronic or acute, for first or subsequent episodes, for the acute episode or for promoting recovery ${ }^{4}$ and, now, from the Girgis et al trial, probably in the longer-term when used from the first episode onwards. No doubt there are differences between different individual antipsychotic drugs in terms of potency, efficacy and side-effects. But these differences have been overplayed and systematically linked to a class effect of the atypicals.

†See pp. 281-288, this issue.
The story of the atypical antipsychotics is a tale of the triumph of profit over patient benefit, of marketing over ethics. For the past 15-20 years, most psychiatrists, like Girgis et al, have held the view that the atypical antipsychotics are more efficacious and safe than the older typicals. Where is the evidence that there is a unifying chemical structure for, or a clinically important difference in, the efficacy or effectiveness of 'neuroleptics', 'major tranquillisers', and 'conventional', 'typical', 'atypical', 'first-generation' and 'second-generation' antipsychotics? Is the ever changing terminology part of the fog generated by pharmaceutical companies to increase profits by the simple equation that 'new is better'? Perhaps the importance of these 'classes' lies not in their scientific or medical usefulness, but as an example of some of the most effective marketing in pharmaceutical history - a history worth examining briefly.

\section{The birth of the antipsychotics}

The first controlled trial of chlorpromazine took place on a 'back' ward in Birmingham in $1954 .{ }^{5}$ Chlorpromazine was given to 27 chronically overactive patients with psychosis (three described as 'senile') and alternated with placebo for varying periods to ascertain the drug's impact on behaviour over 22 weeks. Each patient acted as their own control, and they and the ward staff, who assessed patient behaviour on a daily basis, were masked as to whether the patient was receiving placebo or chlorpromazine. The best effects were seen if the drug was given at $150 \mathrm{mg}$ for 6 weeks continuously; switching to placebo in those who had responded produced deterioration. Importantly, the content of the patients' psychotic experiences was unaltered. The drug calmed about two-thirds of the patients, at least to some degree; a third were behaviourally unchanged; and both positive effects and side-effects were dose-related. Interestingly, during the 2-week placebo period, at the start all patients improved, but this improvement disappeared for those who did not take chlorpromazine in the subsequent period.

The obvious interest the staff took in the patients during the trial and the notes of optimism in this 1954 study are a testament to the importance of hope in the context of such a disabling and stigmatising illness. Until this time, patients were placed on wards 
from which they were often never discharged and 'treatments' were crude. Within 10 years, the 'neuroleptic era' was well under way and, for the first time since moral management, psychiatry was driven by a sense of therapeutic optimism. ${ }^{6}$ Concurrently, with Kuhn's discovery of imipramine in 1957, a new science was emerging. The different psychological effects of some tricyclic structures (antidepressants) and others (antipsychotics) generated considerable excitement, and before long new theories suggesting a link between chemical structure and psychotropic effect were being considered. For example, whether a tricyclic chemical was an antidepressant or an antipsychotic was thought to be determined by the angle of the planes of the rings in the tricyclic molecule. This led to speculation that there were different brain mechanisms underpinning depression and schizophrenia. ${ }^{7}$

These new developments and theories raised the possibility that advances in the laboratory could, perhaps, modify the brain processes underlying psychosis and depression. These were the beginnings of the new science of psychiatry. This was not the old 'science' of phenomenology allied with social exclusion and behavioural control in the asylum; this was a science that married the chemists' laboratory with the psychiatric ward. It was simply a matter of time before more refined drugs would be developed that could selectively treat different mental states and illnesses. It is easy to miss an important fact here: this also marks the birth of a new industry. ${ }^{8}$

\section{The rise of the 'atypicals'}

In the early 1960s, clozapine was synthesised. As a dibenzamine, it was thought that it would be an antidepressant. However, clozapine turned out to be an antipsychotic, but unlike other antipsychotics, there was no evidence of any extrapyramidal effects in animal studies. ${ }^{7}$ As a first-line treatment for schizophrenia in high-income countries, clozapine came and went relatively quickly: its licence was withdrawn in Europe and North America in 1975 when eight patients in Finland died from agranulocytosis.

Clozapine's mode of action was, nevertheless, different from other antipsychotics in that its clinical potency did not correlate with its ability to block dopamine $\mathrm{D}_{2}$ receptors, and the lower rate of extrapyramidal side-effects (EPS) suggested a different mode of antipsychotic action. This old drug, with its 'new' and 'atypical' mode of action, was re-introduced in the UK in 1990 (subject to strict blood monitoring in high-income countries) for the treatment of 'treatment-resistant schizophrenia' ${ }^{4}$ - that is, schizophrenia not responding to the old, typical antipsychotics. Clozapine has continued to be a possible first-line treatment in low-income countries.

The concept of atypicality, associated with the revival of clozapine, gave hope that there would be a class of drugs with less severe side-effects, especially EPS and tardive dyskinesia. Atypicality also provided a powerful marketing tool for the industry. A number of new antipsychotics followed, each claiming to have a different mode of action: for example, risperidone blocking serotonin receptors as well as $\mathrm{D}_{2}$ receptors; ${ }^{9}$ and each claiming greater efficacy and/or fewer side-effects. A new class of antipsychotics was born. Many psychiatrists, especially researchers closely connected to the drug industry, claimed that the emergence of the atypicals was a revolution in schizophrenia treatment and research comparable to the introduction of the original antipsychotic, chlorpromazine. ${ }^{6}$ Even the more sceptical thought that the advent of the atypicals was an important advance: patients could at least choose between being stiff and putting on weight. Indeed, it is a testament to the success of this marketing exercise that the National Institute for Health and
Clinical Excellence (NICE) undertook a Technology Appraisal of the atypical antipsychotics in $2002 .^{10}$

\section{Decline and fall}

Doubts about the superiority and integrity of the atypicals emerged over 10 years ago. Geddes et $a^{11}$ published a metaregression suggesting that the apparent superiority of the atypicals was the result of not comparing like with like. Many of the trials (mainly sponsored by drug companies) compared moderate doses of an atypical with a higher dose of a potent typical such as haloperidol. The atypical drug thereby appeared to be more efficacious (e.g. fewer drop outs in an intention-to-treat analysis) and associated with comparatively lower rates of EPS. The authors estimated that if the dose of the typical antipsychotic was $12 \mathrm{mg}$ or less of haloperidol (or equivalent), there was no difference in efficacy or overall tolerability. Although neither confirmed nor disproved by later meta-analyses, this view has considerable face validity, especially for trials completed within 8-10 weeks: a drug liable to produce significant early-onset side-effects, such as EPS and sedation, is likely to have a greater drop-out rate in the first weeks of treatment than one with later-onset side-effects such as obesity.

More recently, two effectiveness trials comparing atypicals and typicals (now called second-generation and first-generation antipsychotics (SGAs and FGAs)) have provided confirmation that there is no clear difference in effectiveness between these classes. ${ }^{12,13}$ The CUtLASS trial ${ }^{13}$ appeared to show that there is no difference in efficacy between the SGAs and FGAs, although the former cost more. And although the CATIE trial suggested olanzapine was more efficacious than others, ${ }^{12}$ this is not a 'class' effect. That there are no consistent differences between atypicals and typicals, SGAs and FGAs, has been confirmed in a recent meta-analysis of 150 trials of these drugs: in 95 of these trials the FGA comparator was a high-potency FGA - haloperidol frequently at high doses. ${ }^{14}$

In the recently updated NICE schizophrenia guideline we also found that there were no consistent differences between atypicals and typicals, SGAs and FGAs; there were no important differences between any of the antipsychotics in terms of clinical or costeffectiveness (except for clozapine in treatment-resistant schizophrenia); the side-effects varied from drug to drug and were not determined by class; and all the antipsychotics were associated with potentially serious dose-related and other side-effects. ${ }^{4}$ Although some of the newer drugs are associated with lower rates of EPS/tardive dyskinesia, they are also linked to different and equally severe side-effects such as diabetes, and some other newer drugs may have similar rates of EPS to the older drugs. From Girgis et al in this issue, it now seems unlikely that there are any longerterm benefits for using atypicals or SGAs in the first episode.

In creating successive new classes of antipsychotics over the years, the industry has helped develop a broader range of different drugs with different side-effect profiles and potencies, and possibly an increased chance of finding a drug to suit each of our patients. ${ }^{4}$ But the price of doing this has been considerable - in 2003 the cost of antipsychotics in the USA equalled the cost of paying all their psychiatrists. The story of the atypicals and the SGAs is not the story of clinical discovery and progress; it is the story of fabricated classes, money and marketing. The study published today is a small but important piece of the jigsaw completing a picture that undermines any clinical or scientific confidence in these classes. With the industry reputation damaged by evidence of selective publishing and its deleterious effects, ${ }^{15,16}$ and the recent claims that trials of at least one of the new 
atypicals have been knowingly 'buried', ${ }^{2}$ it will take a great deal for psychiatrists to be persuaded that the next new discovery of a drug or a class will be anything more than a cynical tactic to generate profit. In the meantime, perhaps we can drop the atypical, second-generation, brand new and very expensive labels: they are all just plain antipsychotics.

Tim Kendall, National Collaborating Centre for Mental Health, Royal College of Psychiatrists' Research Unit, 4th Floor, Standon House, 21 Mansell Street, London E1 8AA, UK. Email: tim.kendall@cru.rcpsych.ac.uk

First received 31 Jul 2010, final revision 12 Apr 2011, accepted 26 May 2011

\section{Acknowledgements}

I thank Clare Taylor, Tim Kember and Marie Halton for help in the preparation of this manuscript.

\section{References}

1 Girgis RR, Phillips MR, Li X, Li K, Jiang H, Wu C, et al. Clozapine v. chlorpromazine in treatment-naive, first-episode schizophrenia: 9-year randomised clinical trial. Br J Psychiatry 2011; 199: 281-8.

2 Spielmans, Gl, Parry PI. From evidence-based medicine to marketing-based medicine: evidence from internal industry documents. Bioethic Inq 2010; 7: $13-29$.

3 Leucht S Kissling W, Davis JM. Second-generation antipsychotics for schizophrenia: can we resolve the conflict. Psychol Med 2009; 39: 1591-602.

4 National Collaborating Centre for Mental Health. Schizophrenia: Core Interventions in the Treatment and Management of Schizophrenia in Adults in Primary and Secondary Care (updated edition). British Psychological Society and Royal College of Psychiatrists, 2010.
5 Elkes J, Elkes C. Effect of chlorpromazine on the behaviour of chronically overactive psychotic patients. BMJ 1954; 2: 560-5.

6 Kerwin, RW. Clozapine: back to the future for schizophrenia research. Lancet 1995; 345: 1063-4.

7 Hippius H. The history of clozapine. Psychopharmacology 1989; 99: S3-5

8 Healy D. The Creation of Psychopharmacology. Harvard University Press, 2002.

9 Janssen PA, Niemegeers CJ, Awouters F, Schellekens KH, Megens AA, Meert TF. Pharmacology of risperidone (R64766), a new antipsychotic with serotonin-S2 and dopamine D2 antagonistic properties. J Pharmacol Exp Ther 1988; 244: 685-93.

10 National Institute for Clinical Excellence. Guidance on Use of Newer (Atypical) Antipsychotic Drugs for the Treatment of Schizophrenia. Technology Appraisal no. 43. NICE, 2002.

11 Geddes J, Freemantle N, Harrison P, Bebbington P. Atypical antipsychotics in the treatment of schizophrenia: systematic overview and meta-regression analysis. BMJ 2000; 321: 1371-6.

12 Lieberman JA, Stroup TS, McEvoy JP, Swartz MS, Rosenheck RA, Perkins DO, et al. Effectiveness of antipsychotic drugs in patients with chronic schizophrenia. N Engl J Med 2005; 353: 1209-23.

13 Jones PB, Barnes TRE, Davies L, Dunn G, Lloyd H, Hayhurst KP, et al. Randomized controlled trial of the effect on quality of life of second- vs firstgeneration antipsychotic drugs in schizophrenia: Cost Utility of the Latest Antipsychotic drugs in Schizophrenia Study (CUtLASS 1). Arch Gen Psychiatry 2006; 63: 1079-87.

14 Leucht S, Corves C, Arbter D, Engel RR, Li C, Davis JM. Second-generation versus first-generation antipsychotic drugs for schizophrenia: a metaanalysis. Lancet 2009; 373: 31-41.

15 Whittington CJ, Kendall T, Fonagy P, Cottrell D, Cotgrove A, Boddington E. Selective serotonin reuptake inhibitors in childhood depression: systematic review of published versus unpublished data. Lancet 2004; 363: 1341-5.

16 Turner EH, Matthews AM, Linardatos E, Tell RA, Rosenthal R. Selective publication of antidepressant trials and its influence on apparent efficacy. $N$ Engl J Med 2008; 358: 252-60. 